\title{
Optimization of Engine Operating Parameters for Turpentine Mixed Diesel Fueled DI Diesel Engine Using Taguchi Method
}

\author{
KARTHIKEYAN.R \\ Professor, Dept. of Mechanical Engineering, Adhiparasakthi Engineering College \\ Melmaruvathur. Tamil Nadu, India \\ E-mail: r.karthi1968@gmail.com \\ NALLUSAMY.N \\ Professor, Dept. of Mechanical Engineering, Sri Venkateswara College of Engineering \\ Sriperumepudur, Tamil Nadu, India
}

ALAGUMOORTHI.N

Professor, Dept. of Mechanical Engineering, Pondicherry Engineering College

Puducherry, India

ILANGOVAN.V

Professor, Dept. of Mechanical Engineering

Karpagavinayagar College of Engineering and Technology

Maduranthagam, Tamil Nadu, India

\begin{abstract}
The present investigation used Turpentine; a volatile fraction of pinus resin as an alternate fuel for diesel fuel. Generally, turpentine possesses moderate cetane number which is not sufficient to operate existing diesel engine. However, this could be admissible along with diesel fuel in the form of blends. Keeping this in mind experiments have been conducted using blends of turpentine and diesel fuel to study its replaceability, performance and emission behaviour. As the investigation involves three parameters such as blend proportion, injection timing and injection pressure, a simultaneous optimisation method called Taguchi was used in the work. This method requires fewer numbers of trials for fixing optimum levels. This is the primary advantage of this method. As per this method nine trials were experimented and its results were used for optimisation. In addition, an ANOVA was also performed for the parameters to evaluate its percentage contribution over the desired output. The results of the taguchi experiment showed that the $40 \mathrm{~T}$ blend $(40 \%$ turpentine and $60 \%$ diesel) performed better at $29^{\circ} \mathrm{BTDC}$ injection timing and at 180 bar injection pressure than other blends and had a capacity to cold start the engine. Using the optimum levels, a full range experiment was also conducted using 40T blend to compare its performance and emission behaviour with standard diesel operation. The results of the full range experiment showed that the 40T blend offered approximately $2.5 \%$ higher brake thermal efficiency than diesel baseline operation without much worsening the exhaust emission.
\end{abstract}

Keywords: Turpentine, Diesel engine, Taguchi method, Optimisation

\section{Introduction}

Ever increasing fuel price, continuous addition of on road vehicles, fast depleting petroleum resources and continuing accumulation green house gases are the main reasons for the development of alternative fuels. Many alternative fuels are indentified and tested successfully in the existing engine with and without engine modification. However, research is still continuing in this field to find the best alternative fuel for the existing petro fuel.

Most of the alternative fuels identified today are bio fuels and are having one or few undesirable fuel characteristics which are not permitting them to replace the existing petro fuel completely (Devan.P.K, and 
Mahalakshmi.N.V (2010)). However, the various admission techniques experimented by the researchers are giving good solution to apply larger fraction of replacing fuel in the existing engine.

Bio fuels are renewable, eco-friendly (Robert et al (1995)) and are obtained from bio resources such as plants and animals. Compared to animals, plants are the major contributors in supplying of bio fuels. Generally, plants yield two types of oils namely triglyceride oils (TG oils) and turpene oils (light oil). Of which, the triglyceride oils are obtained from plant seeds but turpene oils are obtained from all parts of the plant (Karthikeyan R. and Mahalakshmi N.V. (2005)). Also, TG oils are comparatively higher viscous than terpene oils and possessing appreciable fuel properties. In addition, this kind of oils are abundant in some plant species namely eucalyptus, pine tree etc.

The present investigation used one such oil called Turpentine; a volatile fraction of oleoresin in a DI diesel engine as an alternate fuel for diesel oil. But, the insufficient cetane number of turpentine prevents the complete replacement of diesel fuel from the diesel engine. However, the blended form of diesel and turpentine displace diesel fuel to large extent and does not require any engine modification. Hence, this investigation mainly focused on the determination of maximum possible diesel replacement by turpentine oil and suitable engine operating parameters for maximum blend operation.

Table 1 details the properties of turpentine and its comparison with diesel and gasoline. From the table it is seen that the properties of turpentine fall in between the properties of petrol and diesel fuel. Also, few of them are also closer to that of diesel oil (Karthikeyan R. and Mahalakshmi N.V. (2007)) (Table 1).

Usually, alternative fuels are tested in the existing engines that use petrol or diesel as fuel. These engines are specially designed for it and also optimised for it. Using of new kind of fuel in this engine may lead to change of performance, which may not be optimum for it. Hence, the test engine parameters such as injection timing and injection pressure must be modified for the new kind of fuel considered for the application. This experiment involves three parameters such as injection timing, injection pressure and blends composition. Hence, a method called Taguchi was tried in this experiment to optimise the above parameters in lesser number of trials.

After the determination of optimum level of parameters, a full range experiment was conducted using the selected blend at the optimum engine setting. The results of the full range of experiment were then compared with standard diesel operation. An ANOVA was also performed for the involved parameters to check the percentage contribution of parameters over the desired response.

\subsection{Turpentine}

Turpentine is a kind of volatile essential oil obtained from oleoresin exuded from the pine tree, when subjected to mechanical injury. Pine trees are the world's known tallest, biggest, oldest and most populated trees (even 5000 year old trees are known to exist). Genus Pinus is one of the most widely distributed genera of trees in the northern and southern hemisphere, extending from the polar region to the tropics.

Pine trees (coniferous trees) naturally has a kind of resin, which is rich in chemical compounds such as terpenes, fatty acids, waxes, tannins and phenolics. This has been collected from the tree by bark chipping and borehole methods. The main function of the resin is to protect the tree against insect, pests and diseases, and act as energy reserves. The crude oleoresin is converted into its primary fractions called gum rosin and turpentine by steam distillation process. Pine trees can be easily cultivated in wastelands and they need very little or no water and human effort.

\section{Experimental setup}

The engine setup shown in Figure 1 used for experimental investigation is a single cylinder, air cooled, and vertical and direct injection diesel engine. It is capable of developing $4.4 \mathrm{~kW}$ at a constant speed of $1500 \mathrm{rpm}$ and coupled to an eddy current dynamometer. The inlet side of the engine consists of anti-pulsating drum, air heater and air temperature measuring device. The exhaust side of the engine consists of EGT indicator, exhaust gas analyzer and smoke sampler. The setup also consists of a separate fuel measuring device for measuring consumption of diesel-turpentine blends. A 64 bit DAQ system is also provided with the test rig to acquire crank angle and cylinder pressure data.

\section{Methodology}

Bi-fueling or blending is the simplest technique for admitting low cetane fuels in high compression engines. According to this method the fuel selected for investigation is mixed with standard diesel oil in various proportions on volume basis and its properties such as calorific value and viscosity were evaluated before admission. 
Among the prepared blends, the low turpentine blends such as $10 \mathrm{~T}$ and $20 \mathrm{~T}$ were not considered for experimentation as these blends are not providing higher diesel replacement. Other blends such as 30T, 40T and 50T were considered for experimentation. This experiment involves three parameters such as injection timing, injection pressure and blends composition. Hence, a method called Taguchi was tried in this experiment to optimise the above parameters in lesser number of trials.

\subsection{Taguchi Method of Optimisation}

Taguchi method is a simplest method of optimising experimental parameters in less number of trials. The number of parameters involved in the experiment determines the number of trials required for the experiment. More number of parameters led to more number of trials and consumes more time to complete the experiment. Hence, a method called 'Taguchi' was tried in the experiment to optimise the levels of the parameter involved in the experiment.

This method uses an orthogonal array to study the entire parameter space with only a small number of experiments (George et al., 2004). To select an appropriate orthogonal array for the experiments, the total degrees of freedom need to be computed. The degrees of freedom are defined as the number of comparisons between design parameters that need to be made (Yang and Tarng., 1998). The present study uses three factors at three levels and hence, an $\mathrm{L}_{9}$ orthogonal array with four columns and nine rows were used (Palani and Murugan., 2006) for the construction of experimental layout (Table 2). The $\mathrm{L}_{9}$ has four columns and nine rows and the parameters such as injection timing, injection pressure and blend proportions are arranged in column 1,2 and 4, and column 3 is used for the error of the experiment (Table 3).

According to this layout, nine experiments were designed and trials were selected at random, to avoid systematic error creeping into the experimental procedure (Palani et al., 2004). For each trial the brake thermal efficiency was calculated and used as a response parameter. Taguchi method uses a parameter called signal to noise ratio $(\mathrm{S} / \mathrm{N})$ for measuring the quality characteristics. There are three kinds of signal to noise ratios are in practice. Of which, the higher-the-better $\mathrm{S} / \mathrm{N}$ ratio was used in this experiment because this optimisation is based on higher BTE. The taguchi method used in the investigation was designed by statistical software called 'Minitab Release $15^{\prime}$ to simplify the taguchi procedure and results.

A full range experiment for the selected blend was also conducted for after modifying the engine operating parameters. This is mainly to compare the performance and emission characteristics of turpentine-diesel blend with standard diesel operation.

\section{Results and Discussion}

\subsection{Taguchi Method of Optimisation}

The present study uses three factors at three levels and each one has two degrees of freedom. Also, the interactions between the parameters are neglected as the parameters are independent. Hence, an $\mathrm{L}_{9}$ orthogonal array with four columns and nine rows were used to design taguchi experiment. The factors considered for experiment and its levels are shown in Table 2. The experimental layout of $\mathrm{L}_{9}$ orthogonal array used for the experiment is given in Table 3 and 4 . The list of S/N ratio for the response parameter (BTE) is given in Table 5.

Figure 2 shows the response graph of taguchi experiment. It was used for selecting the optimum level of the parameters. The peak value of each graph is considered as the optimum points as these points are offering highest $\mathrm{S} / \mathrm{N}$ ratios. The optimum points obtained from the response graph is listed in Table 6 . These optimum parameters were used for the full range experiment.

\subsection{Analysis of Variance (ANOVA)}

The purpose of analysis of variance (ANOVA) is to investigate the percentage contribution of variance over the response parameter. Statically, there is a tool called an F-test named after Fisher to check the significance of variance on the output characteristic (Yang and Tarng., 1998). Usually, when F $>4$ means the change of the design parameter has a significant effect over the output characteristic. Table 7 indicates the percentage contribution of various parameters involved in Taguchi experiments. A parameter called blend proportion has the highest contribution over output characteristic whereas the injection pressure has the lowest contribution compared to other two parameters. This means that the change of injection pressure has insignificant effect over the output characteristics.

\subsection{Experiment of Maximum blend at optimum setting}

Using the optimum levels arrived by Taguchi method of optimisation a full range experiment was conducted and its results were compared with diesel baseline operation. 


\subsubsection{Brake Thermal Efficiency}

Figure 3 shows the variation of brake thermal efficiency of 40T blend with load. It shows comparatively higher brake thermal efficiency for 40T blend than that of reference fuel, at all loads. This may be due to the presence of high volatile turpentine in the blend. Basically, turpentine is a cyclic compound of terpene (Basic element of turpentine). It decomposes easily at low temperature and releases more intermediate compounds (lighter HC fractions) immediately after injection. These may be the reasons for better performance of 40T than that of standard diesel operation.

The presence of turpentine in the blend causes longer ignition delay and rapid combustion. During longer ignition delay engine accumulates more fuel before the commencement of combustion and releases more fraction of heat during the premixed phase of combustion. This leads to higher cylinder pressure and higher brake thermal efficiency.

The improved volatility, increased heat content and improved air entrainment could be the other reasons for higher thermal efficiency of 40T blend.

The maximum brake thermal efficiency obtained with $40 \mathrm{~T}$ blend is $32.5 \%$ and it is $8 \%$ higher than that of standard diesel operation.

\subsubsection{CO Emission}

Figure 4 compares the $\mathrm{CO}$ emission of 40T blend with standard diesel operation. It shows higher $\mathrm{CO}$ emission for $40 \mathrm{~T}$ blend than that of reference fuel at all loads. This may be due to the presence of considerable portion of lighter fuel (turpentine) in the 40T blend. The presence of lighter fuel in the blend causes longer ignition and releases more heat during the first phase of combustion. This leads to higher combustion temperature and higher exhaust gas temperature and consequently yields low volumetric efficiency. Hence, the injected blend finds relatively lower oxygen and emits more $\mathrm{CO}$. This may be one of the main reasons for high $\mathrm{CO}$ emission at all loads.

More fuel admission and poor fuel utilization are the other reasons for high $\mathrm{CO}$ emission at high loads. The $\mathrm{CO}$ emission of $40 \mathrm{~T}$ at full load is $22 \%$ higher than reference fuel.

\subsubsection{HC Emission}

Figure 5 compares the $\mathrm{HC}$ emission of $40 \mathrm{~T}$ blend with standard diesel operation. It shows lower HC emission for $40 \mathrm{~T}$ blend than that of reference fuel at all loads. This may be due to the production of higher combustion temperature, simple molecular structure and unstable nature of turpentine. The higher volatility and better air entrainment are considered as the probable reasons for lower $\mathrm{HC}$ emission.

The $\mathrm{HC}$ emission of $40 \mathrm{~T}$ at full load is $210 \mathrm{ppm}$, which is $35 \mathrm{ppm}$ lower than reference fuel.

\subsubsection{NOx Emission}

Figure 6 shows the variation of NOx emission with engine load. It shows that the NOx emission of 40T blend is higher than standard diesel operation at all loads. This may be due to the cetane suppressing property of turpentine. Usually, low cetane fuels offer longer ignition delay and release more heat during the premixed phase of combustion. This causes higher combustion temperature and enhances the reaction between oxygen and nitrogen and consequently yields more NOx compounds.

The maximum NOx obtained with $40 \mathrm{~T}$ at full load is $1380 \mathrm{ppm}$, which is $220 \mathrm{ppm}$ higher than reference fuel.

\subsubsection{Smoke Intensity}

Figure 7 compares the Bosch Smoke Number (BSN) of 40T blend with standard diesel operation at various engine loads. It is observed that the $40 \mathrm{~T}$ blend shows higher reduction of smoke at all loads. More specifically, at full load, it offers $50 \%$ lower smoke than that of standard diesel operation. This is due to the production of higher combustion temperature and rapid release of intermediate compounds.

The production of intermediate compounds splits the spray particle into finer one and provides least chances for formation of soot. This may be the main reason for lower smoke emission of 40T blend.

\subsubsection{Ignition delay}

Figure 8 compares the cylinder pressure diagram of $40 \mathrm{~T}$ with standard diesel operation at full load. It shows that the combustion of $40 \mathrm{~T}$ occurs approximately 3 degrees later than standard diesel operation and produces peak pressure 5 degrees after TDC.

Figure 9 depicts the variation of ignition delay with engine load. The ignition delay of $40 \mathrm{~T}$ blend is longer than 
that of standard diesel operation at all loads. This may be due to the reduction of charge temperature by evaporative cooling and the higher latent heat of vapourisation.

The ignition delay of $40 \mathrm{~T}$ blend at full load is 11 degrees. It is 3 degrees longer than standard diesel operation.

\subsubsection{Heat Release Rate}

Figure 10 compares the heat release rate of $40 \mathrm{~T}$ blend with standard diesel operation at full load. From the figure, it is seen that the two phase of combustion is clearly visible and distinguishable. The first phase of combustion is higher than that of standard diesel operation as it has low cetane number and offers longer ignition delay. This is the main reason for higher brake thermal efficiency, shorter burn duration and higher peak pressure of 40T blend.

\section{Conclusion}

Based on the experimental investigations conducted on a single cylinder DI diesel engine using Turpentine mixed diesel fuel the following major conclusions are arrived.

1) The results showed that the mixing of turpentine with diesel fuel upto $40 \%$ increases brake thermal efficiency by $1-2 \%$ from the reference fuel.

2) Taguchi method of optimisation predicted optimum level of parameters within 9 trials and the $40 \mathrm{~T}$ blend found working satisfactorily at optimum setting.

3) Comparatively a slighter increment in NOx emission was found while working with $40 \mathrm{~T}$ blend at optimum setting.

4) Approximately 50\% smoke reduction was achieved with $40 \mathrm{~T}$ operation.

5) A smaller on shoot of $\mathrm{CO}$ was found with $40 \mathrm{~T}$ operation at full load.

The results also proved that the blending of turpentine with diesel fuel upto $40 \%$ increases the engine performance without much worsening its emission.

\section{References}

Devan.P.K, and Mahalakshmi.N.V. (2010). Combustion, Emission and Performance Characteristics of Diesel engine Fueled with Eucalyptus oil with an Ignition Enhancer, International Journal of Green Energy, Energy and Environment, Vol.1, No.1, April 2010,pp. 40-49.

Karthikeyan R. and Mahalakshmi N.V. (2005). Performance and emission characteristics of four stroke DI diesel engine fueled with turpentine diesel blends, Proceedings of the ICEF2005 ASME Internal Combustion Engine Division 2005 Fall Technical Conference, Sep 11-14, 2005, Ottawa, Canada.

Karthikeyan R. and Mahalakshmi N.V. (2007). Performance and emission characteristics of a turpentine-diesel dual fuel engine, Energy the International Journal, Vol. 32, No. 7, July 2007, pp. 1202-1209.

P. K. Palani*1, N. Murugan2 and B. Karthikeyan3. (2006). Process parameter selection for optimising weld bead geometry in stainless steel cladding using Taguchi's approach, Materials Science and Technology, 2006 VOL 22 NO 10.

P.K. Palani and N. Murugan. (2006). Ferrite number optimisation for stainless steel cladding by FCAW using Taguchi technique', Int. J. Materials and Product Technology, Vol. 4, 422-429.

P.M. George a,*, Nisha Pillai b, Nisha Shah b. (2004). Optimization of shot peening parameters using Taguchi technique, Journal of Materials Processing Technology, 153-154 (2004) 925-930.

Robert J. Last, Micheal Kruger, Manfred Durnholz. (1995). Emissions and Performance Characteristics of A 4Stroke, Direct Injected Diesel Engine Fueled With Blends of Biodiesel and Low Sulfer Diesel Fuel, SAE Trans., 950054, pp 1-13.

W.H. Yang, Y.S. Tarng. (1998). Design optimization of cutting parameters for turning operations based on the Taguchi method. Journal of Materials Processing Technology, 84 (1998) 122-129. 
Table 1. Physical and chemical properties of turpentine

\begin{tabular}{|l|c|c|c|}
\hline \multicolumn{1}{|c|}{ Properties } & Gasoline & Diesel & Turpentine \\
\hline Formula & $\mathrm{C}_{4}$ to $\mathrm{C}_{12}$ & $\mathrm{C}_{8}$ to $\mathrm{C}_{25}$ & $\mathrm{C}_{10} \mathrm{H}_{16}$ \\
\hline Molecular Weight & 105 & 200 & 136 \\
\hline $\begin{array}{l}\text { Composition } \% \\
\mathrm{Wt}\end{array}$ & $\mathrm{C} \quad 88 \mathrm{H} \quad 15$ & $\mathrm{C} \quad 87 \mathrm{H} \quad 16$ & $\mathrm{C} 88.2 \mathrm{H}$ \\
\hline Density kg/m3 & 780 & 830 & $860-900$ \\
\hline Specific Gravity & 0.78 & 0.83 & $0.86-0.9$ \\
\hline Boiling Point ${ }^{\circ} \mathrm{C}$ & $30-220$ & $180-340$ & $150-180$ \\
\hline Viscosity c St & 0.4 & $3-4$ & 2.5 \\
\hline $\begin{array}{l}\text { Latent Heat of } \\
\text { Vaporization kJ/kg }\end{array}$ & 350 & 230 & 305 \\
\hline $\begin{array}{l}\text { Lower Heating } \\
\text { Value kJ/kg }\end{array}$ & 43,890 & 42,700 & 44,000 \\
\hline Flash Point ${ }^{\circ} \mathrm{C}$ & -43 & 74 & 38 \\
\hline $\begin{array}{l}\text { Auto Ignition } \\
\text { Temperature }{ }^{\circ} \mathrm{C}\end{array}$ & $300-450$ & 250 & $300-330$ \\
\hline $\begin{array}{l}\text { Flammability } \\
\text { limit \%olume }\end{array}$ & 1.4 & 1.0 & 0.8 \\
\hline \begin{tabular}{l} 
Cetane Number \\
\hline
\end{tabular} & $40-55$ & $20-25$ \\
\hline
\end{tabular}

Table 2. Process parameters and their levels

\begin{tabular}{|l|l|l|r|r|r|}
\hline Symbol & \multicolumn{1}{|c|}{ Parameters } & \multicolumn{1}{|c|}{ Units } & Level 1 & Level 2 & Level 3 \\
\hline A & Injection timing & CA BTDC & 27 & 29 & 31 \\
B & Injection Pressure & bar & 170 & 180 & 190 \\
C & Blend & \% Turpentine & 30 & 40 & 50 \\
\hline
\end{tabular}

Table 3. Layout of $\mathrm{L}_{9}$ Orthogonal array

\begin{tabular}{|c|c|c|c|}
\hline A & B & Error & $\mathrm{C}$ \\
\hline 1 & 1 & 1 & 1 \\
\hline 1 & 2 & 2 & 2 \\
\hline 1 & 3 & 3 & 3 \\
\hline 2 & 1 & 2 & 3 \\
\hline 2 & 2 & 3 & 1 \\
\hline 2 & 3 & 1 & 2 \\
\hline 3 & 1 & 3 & 2 \\
\hline 3 & 2 & 1 & 3 \\
\hline 3 & 3 & 2 & 1 \\
\hline
\end{tabular}


Table 4. Layout of Orthogonal Experiments

\begin{tabular}{|c|c|c|}
\hline A & B & $\mathrm{C}$ \\
\hline 27 & 170 & 30 \\
\hline 27 & 180 & 40 \\
\hline 27 & 190 & 50 \\
\hline 29 & 170 & 40 \\
\hline 29 & 180 & 50 \\
\hline 29 & 190 & 30 \\
\hline 31 & 170 & 50 \\
\hline 31 & 180 & 30 \\
\hline 31 & 190 & 40 \\
\hline
\end{tabular}

Table 5. S/ $\mathrm{N}$ ratios of brake thermal efficiency

\begin{tabular}{|r|r|r|r|}
\hline Inj.Timing & Inj.Pressure & Blend & BTE SNR \\
\hline 27 & 170 & 30 & 28.04 \\
27 & 180 & 40 & 28.25 \\
27 & 190 & 50 & 27.27 \\
29 & 170 & 40 & 28.72 \\
29 & 180 & 50 & 27.85 \\
29 & 190 & 30 & 28.59 \\
31 & 170 & 50 & 26.85 \\
31 & 180 & 30 & 27.98 \\
31 & 190 & 40 & 28.01 \\
\hline
\end{tabular}

Table 6. Optimum Value of Parameters

\begin{tabular}{|l|l|}
\hline \multicolumn{1}{|c|}{ Parameters } & \multicolumn{1}{c|}{ Value } \\
\hline Injection timing & $29^{\circ} \mathrm{BTDC}$ \\
\hline Injection pressure & $180 \mathrm{bar}$ \\
\hline Blend proportion & $40 \mathrm{~T}$ \\
\hline
\end{tabular}

Table 7. ANOVA for the variance involved in Taguchi experiment

\begin{tabular}{|l|r|r|r|r|l|}
\hline & & & \multicolumn{1}{|l|}{} & Contribution (\%) \\
\hline Parameters & DOF & \multicolumn{1}{|l|}{ SS } & MS & F & \\
Inj.Pressure & 2 & 0.895 & 0.469 & 72.15 & 32 \\
Blend & 2 & 0.084 & 0.019 & 2.9 & 3 \\
Error & 2 & 1.76 & 0.905 & 139.23 & 63 \\
Total & 2 & 0.06 & 0.0065 & & 2 \\
\hline
\end{tabular}




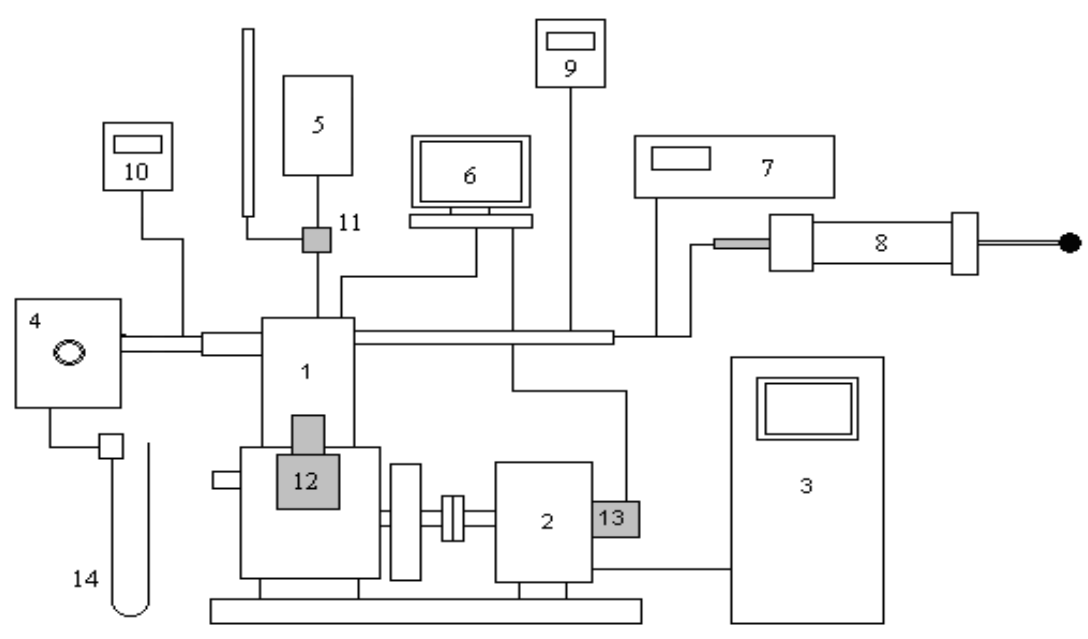

Figure 1. Experimental setup

1 Diesel Engine, 2 Eddy current Dynamometer, 3 Dynamometer Control, 4 Anti pulsating Drum, 5 TD blends, 6 P-IV computer with DAQ, 7 Gas Analyzer Fumigator, 8 Smoke sampling pump Turpentine, 9 Exhaust temperature indicator, 10 Air inlet temperature indicator, 11 Two way valve, 12 Fuel Injection Pump, 13 Crank angle encoder, 14 Manometer.

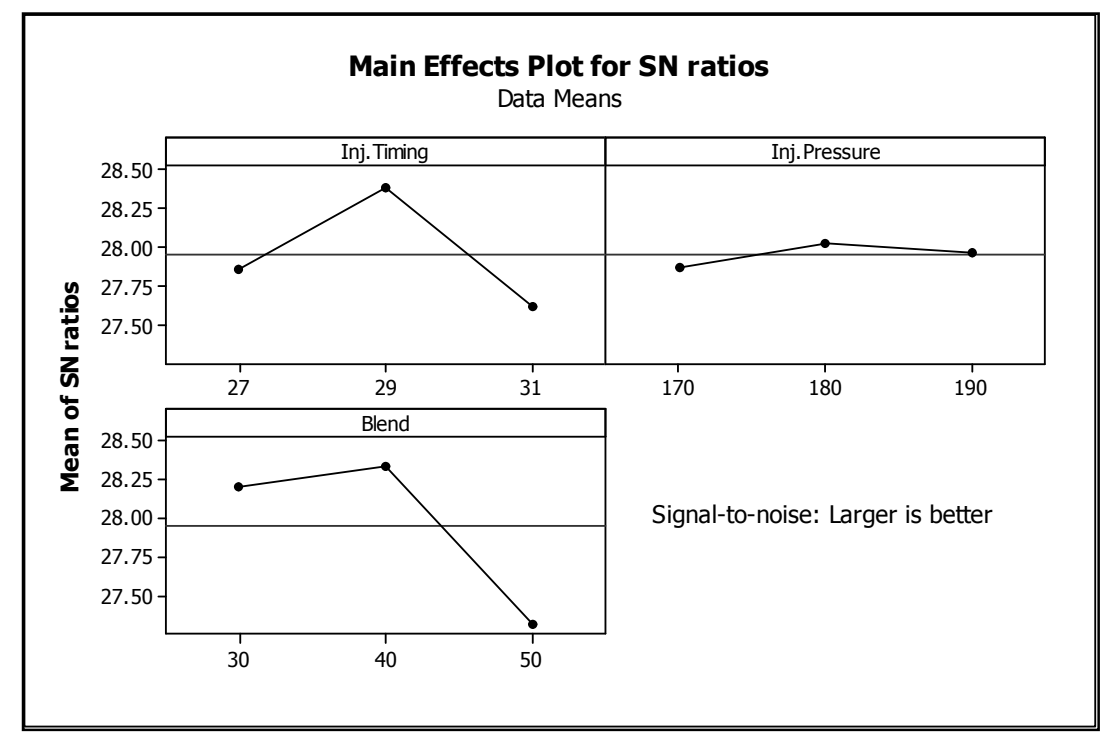

Figure 2. Response graph for orthogonal experiments

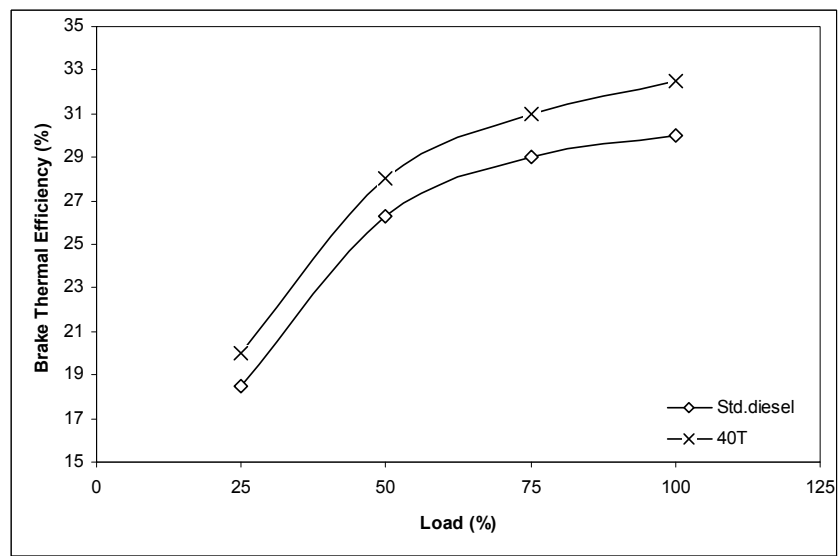

Figure 3. Variation of brake thermal efficiency with load 


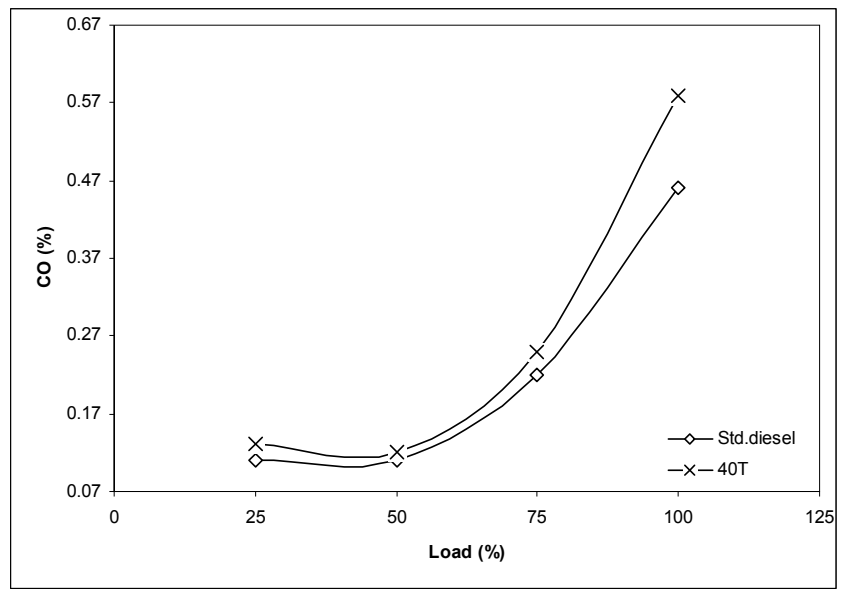

Figure 4. Variation of CO Emission with load

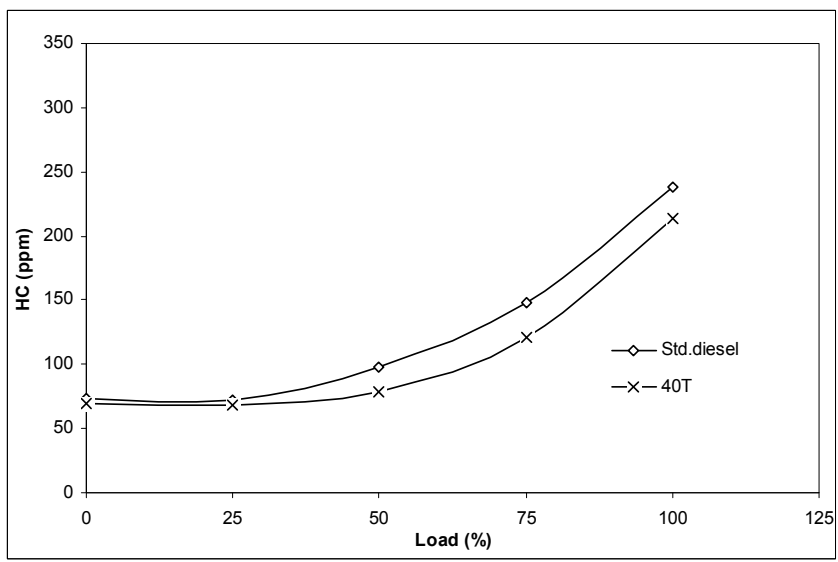

Figure 5. Variation of HC Emission with load

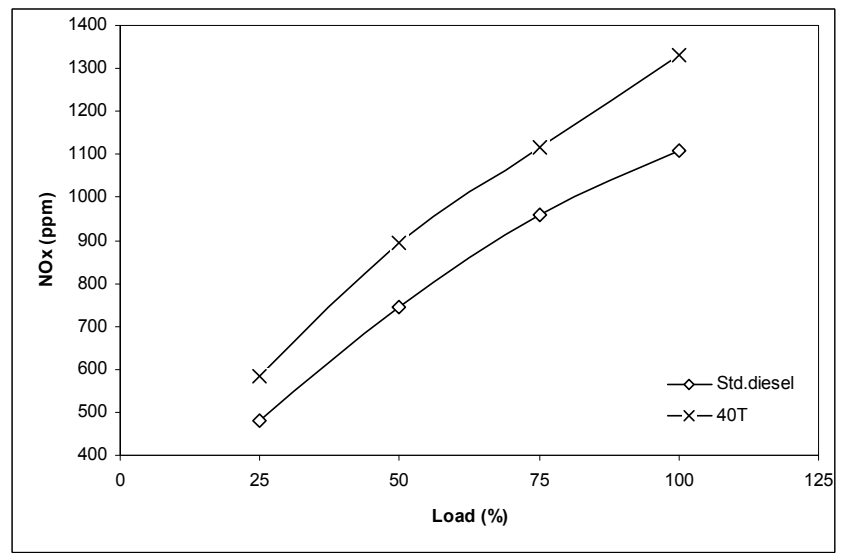

Figure 6. Variation of NOx Emission with load 


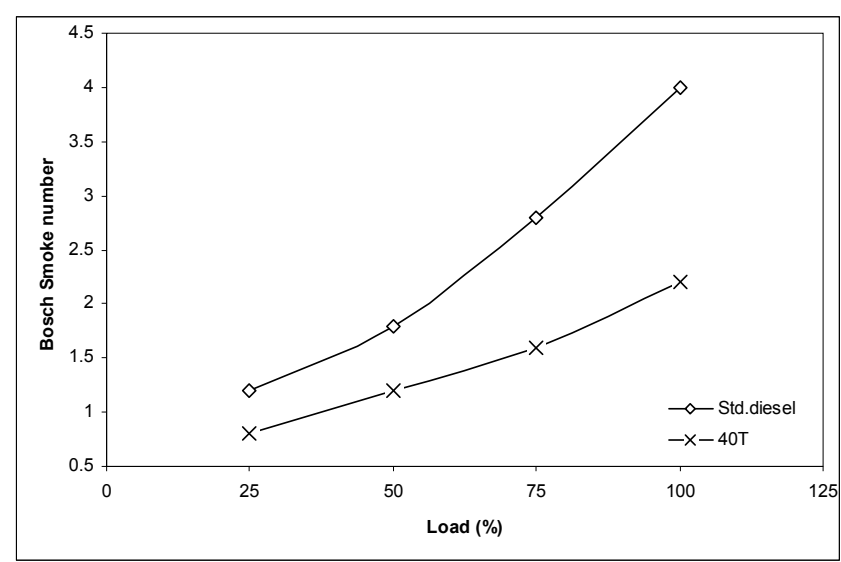

Figure 7. Variation of Bosch Smoke Number with load

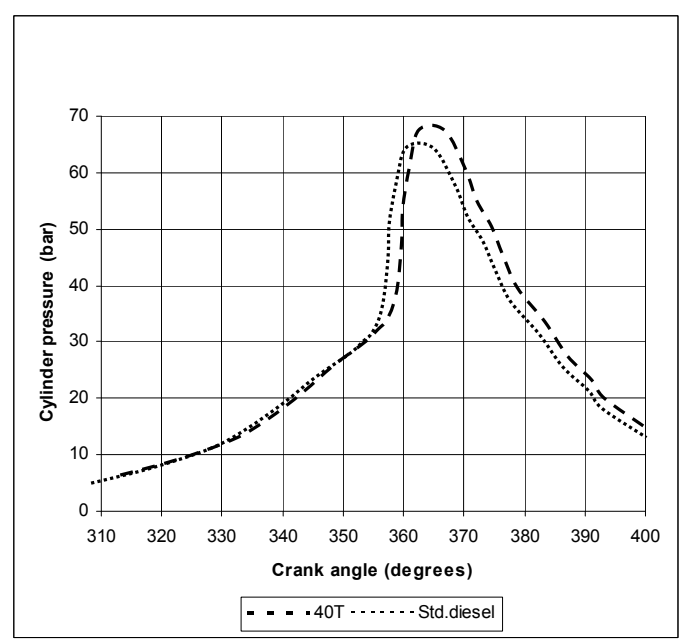

Figure 8. Variation of cylinder pressure with crank angle at full load

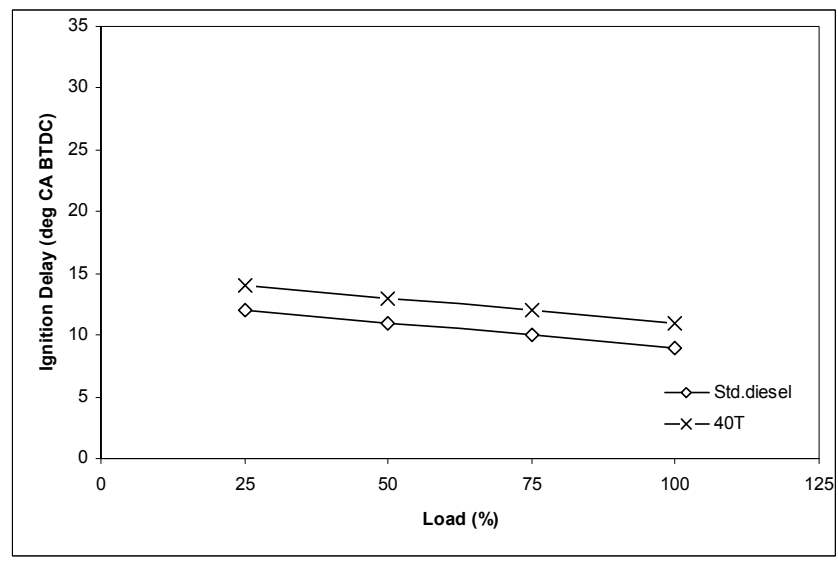

Figure 9. Variation of ignition delay with load 


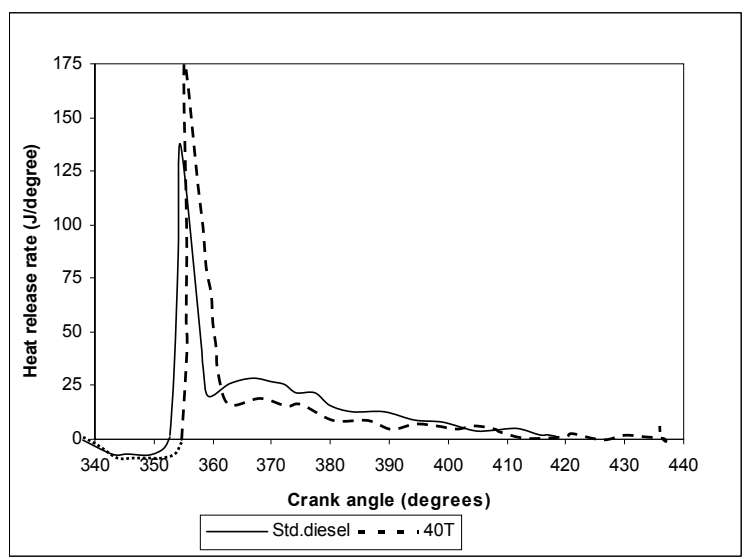

Figure 10. Variation of net heat release rate at full loads 